\title{
Nanomaterials in the environment
}

\author{
Bozena Mrowiec ${ }^{1, *}$ \\ ${ }^{1}$ University of Bielsko-Biala, Institute of Environmental Protection and Engineering, ul. Willowa 2, \\ 43-300 Bielsko-Biala, Poland
}

\begin{abstract}
This paper considers engineered nanomaterials, deliberately engineered and manufactured to have certain properties and have at least one primary dimension of less than $100 \mathrm{~nm}$. Materials produced with the aid of nanotechnologies are used in many areas of everyday life. Researches with nanomaterials have shown that the physiochemical characteristic of particles can influence their effects in biological systems. The field of nanotechnology has created risk for environment and human health. The toxicity of nanoparticles may be affected by different physicochemical properties, including size, shape, chemistry, surface properties, agglomeration, solubility, and charge, as well as effects from attached functional groups and crystalline structure. The greater surfacearea-to-mass ratio of nanoparticles makes them generally more reactive than their macro-sized counterparts. Exposure to nanomaterials can occur at different life-cycle stages of the materials and/or products. The knowledge gaps limiting the understanding of the human and environment hazard and risk of nanotechnology should be explained by the scientific investigations for help to protect human and environmental health and to ensure the benefits of the nanotechnology products without excessive risk of this new technology. In this review are presented the proposal measurement methods for NMs characteristic.
\end{abstract}

\section{Introduction}

Development directions and an exponential growth of nanotechnology and the wider application of nano-scale materials are referred to as the next industrial revolution. In the $21^{\text {st }}$ century nanotechnology is seen as a transformative technology, which has the potential to stimulate scientific innovation and it being important in our daily lives from human health to electronics $[1-4,31]$. It was stated that more than 1600 consumer products are listed in a database to be containing engineered nanomaterials (ENMs) [5]. The International organization for Standardization (ISO) classified nanomaterials into three main groups: nanoparticles (all three dimensions between 1 and $100 \mathrm{~nm}$ ); nanoplates (one dimension between 1 and $100 \mathrm{~nm}$ ); and nanofibers (two dimensions between 1 and $100 \mathrm{~nm}$ ). Manufactures ENMs comprise seven main classes: carbonaceous nanomaterials (e.g. carbon nanotubes); semiconductors (e.g. quantum dots); metal oxides (e.g. zinc oxide); nanopolymers (e.g. dendrimers); nanoclays; emulsions (e.g. acrylic latex); and metals (e.g. silver) $[2,8,31]$. In order from the most to the least often produced they can be presented as

\footnotetext{
*Corresponding author: bmrowiec@ath.bielsko.pl
} 
follows: carbon black $>\mathrm{TiO}_{2}>\mathrm{SiO}_{2}>\mathrm{ZnO}>\mathrm{Fe}$ and $\mathrm{FeO}_{\mathrm{x}}>\mathrm{Al}_{2} \mathrm{O}_{3}>\mathrm{CeO}_{2}>\mathrm{CNT}>\mathrm{Ag}[2$, 6 , 7]. The most common applications of engineered nanopatricles are: personal care products, sunscreens, pigments, polishing agents, photocatalysts, detergents, agrichemicals, window panes and ceramic tiles $\left(\mathrm{TiO}_{2}, \mathrm{ZnO}, \mathrm{CeO}_{2}, \mathrm{SiO}_{2}, \mathrm{Al}_{2} \mathrm{O}_{3}\right.$, ); catalysts, bactericides, groundwater remediation, paints, food packaging, pharmaceutical products, medical implants, textiles ( $\mathrm{Au}, \mathrm{Ag}, \mathrm{Cu}, \mathrm{Fe})$; electronics, solar panels, bioimaging (CdSe, $\mathrm{CdTe})$; drug delivery, chemical sensors (multi-funcjonal polimers - dendrimers); super capacitors, hydrogen storage, ultra-high-strength materials, automobile parts (carbon nanotubes, fullerenes) $[4,10,20,22,26]$. The extensively using of nanomaterials in diverse consumer products causes their release and subsequently accumulate in the environment. Most assessments suggest very low ENMs mass concentrations $(<\mu \mathrm{g} / \mathrm{L})$ are likely. However, the data on the prevalence of engineered nanoparticles (ENPs) use and the release of ENPs into the environment is limited. This lack of data poses a significant hurdle to accurate risk assessment for NMs. However, there is an ongoing debate about the potential risks of ENM and nanotechnologies. It is because, that the nanomaterials can be released to the environment at any stage of life cycle of products (LCA- Life Cycle Assessment), from the manufacture, use, and disposal or recycling processes, therefore nanotechnology could lead to environmental hazards and adverse health effect $[11,20,21,31]$. Due to the rapidly increasing production and use of ENM it is self-evident that aspects of danger must be fully recognized, because it may have important long-term consequences for the human health and the environment.

This paper is a review, which focuses on the issues of the impact of nanomaterials on the environment and possibilities of their determination and analyses in environmental samples for risk assessment.

\section{Nanomaterials sources}

Release of nanomaterials to the environment can be derived from natural or anthropogenic sources. Photochemical reactions, soil erosion by wind or water, forests fires or volcanic eruption and shedding skin and hair by animals, are known as the natural processes which produce and emit very little amount of nanoparticles.

The anthropogenic sources are:

1. Production processes of engineered nanoparticles and nanomaterials. Release during production may occur through leaks into water and air in closed systems or open production processes.

2. Handling and use of nanomaterials and nanoproducts. Handling and use covers several process-related stages e.g. handling of powders, diffuse emission from production plants, mechanical treatment of nanomaterials.

3. Aging of nanoproducts. Aging encompasses all processes taking place in the environment such as selective degradation, wash-out, increased brittleness of the material.

4. Utilization of waste containing nanomaterials (end of life). This group include mainly unwanted or incidental release waste re-use or recycling, waste disposal and incineration, wastewater treatment, and agricultural use of sewage sludge $[1,4,9,11,12,22]$.

Currently yet, there are limited data on the nature and magnitude of potential releases from different sources, transport ways and transformations in the environment.

\section{Toxicity of nanomaterials}

Nanotoxicology represents a new branch of toxicology to address the adverse health effects caused by nanomaterials [12]. But, still is lack a fundamental understanding of how 
nanomaterials interact with living system and, thus, science is not yet in a position to assess the relevant end-points for nanomaterial toxicity. At the same time, we are faced with an onslaught of new nanomaterials for which testing or screening of toxicity is required. To resolve this situation, reliable methods for assessment of nanomaterial toxicity are needed. [11].

Buzea et al. [12] stated, that the most important parameters which determine the adverse effects of the nanomaterials influence on living organisms are their dose, dimension (size), and durability. Besides, they are also important characteristics, such as: solubility, concentration and agglomeration, shape, surface area, chemical and crystalline structure, surface coating and functionalization. The smaller a particle, the greater its surface area to volume ratio and the higher its chemical reactivity and biological activity. Because of their large surface area, nanoparticles will, on exposure to tissue and fluids, immediately adsorb onto their surface some of the macromolecules they encounter. This may, for instance, affect the regulatory mechanisms of enzymes and other proteins [12, 14, 17-19]. Studies on nanotoxicity are mainly concentrated on empirical evaluation of the toxicity of various nanomaterials, with less regard given to the relationship between nanoparticle properties and toxicity. Therefore scientific articles show different correlations between various physico-chemical properties of nanomaterials and the associated negative effects on living organisms. This approach gives very limited information, and could not be considered adequate for developing assessment of toxicity of seemingly similar nanomaterials.

Nanomaterials released into the environment can react with the components of air, water and soil, which causes, among others, changes in particle charge, surface properties or ability to aggregate [23]. The US National Research Council has indicated that researches with respect to nanomaterials should focus on identifying the so-called. "critical elements of interaction", which are necessary to assess exposure and the risk posed by designed nanomaterials. These critical elements include the physical, chemical and biological changes, which ultimately affect the durability of nanomaterials, their bioavailability/absorption, reactivity and toxicity [24].

Of course, not all nanonaterials are toxic. Sometimes studies performed on the same type of nanomaterials are in disagreement, some studies show their biocompatibility, while others prove their potentially hazardous nature [12-15]. For determine the toxicity of various nanomaterials, it is necessary compare their toxicity to effects caused by known toxic particles. However, the database of studied nanomaterials is still limited. The published results show that the carbon nanotubes (CNT) and fullerenes are very toxic [12, 26-29]. CNT causing significantly more damage to the lungs than carbon black or silica Their aggregates and some carbon blacks can be cytotoxic as asbestos [12]. Also to the group of highly toxic nanomaterials are recommended quantum dots (CdSe, CdTe) and nanogold. To the group of medium toxicity are classified zinc oxide, aluminium oxide, iron oxide, silver and dendrimers, [26-29]. Silver nanoparticles in form of aggregates are more toxic than asbestos [12]. On the other hand, nanomaterials such as titanium oxide, yttrium iron oxide, zirconium oxide, silicon dioxide, silica, silicon nanowires and nanoclay particles are considered to be less toxic [12, 26-29].

Literature data indicate that one mechanism of toxicity of nanoparticles is likely to be induction of reactive oxygen species and the consequential oxidative stress in cells and organs. Response in the form of oxidative stress may appear at different rates depending on the type of nanomaterial. It is thought that the particles of the transition metals greatly accelerate the process. Free radicals - generated in the process of oxidative stress - do cause damage of biological structures - proteins, lipids and DNA molecules. Also the oxidative stress could induce an inflammatory response in cells via activation of transcription factors $[15,22,25]$. Nanomaterials uptake by the body occurs after inhalation exposure (neuronal 
uptake, translocation across lung epithelium), oral (ingestion) and dermal exposure depending on the characteristics of the nanomaterial under investigation $[12,15,22]$.

Currently, a significant problem in studies of nanomaterials toxicity is the fact, that in the majority the most of the in vitro studies are short-term tests, while the impact of nanomaterials on human health and the environment takes place in the conditions of longterm exposure, [30].

\section{Nanometrology}

Possibility of a correct assessment of ENP fate, transport, and toxicity in the environment depends on the ability to analyze ENPs in complex matrices. There are many options for analyzing ENPs in simple matrices. However, validation and application of these tools to analyse of environmental samples, is relatively underdeveloped [20]. The used methods must permit to detect nanomaterials and analyse their physicochemical properties in the media in which humans and ecosystems are exposed to them, such as air, water, soil, consumer products and nanocomposities. Also, the methods must be useful to assess the risk of nanomaterials including toxicological and ecotoxicological studies. It is required, that tools are able to detect nanopatricles in the relevant medium, including cells, fluids and plant tissue [22].

Methods for the nonomaterials analysing can be classified as: detection, quantification, and characterization methods.

- Detection determines ENMs presence or absence. The detection of ENMs alone has limited use, but may be helpful for specific studies such as rapidly screening nanocontaining products.

- ENMs quantification to obtain answers to some specific questions is required, for example: What is the degree of ENP uptake by exposed organisms?

- Characterization methods provide additional details on the physical properties (size, shape) and chemical composition of the NMs. These data help in the analyses of ENMs fate and transformation. But now even, measurement of properties such as size, shape, and reactivity are complicated for environmental samples [20]. Table 1 shows the recommended analytical methods for the determination of nanomaterials characteristics.

Essential problems in nanomaterials analysis concern on: 1) mass detection limit, because engineering nanomaterials are expected to enter in to the environment at very low concentrations (ppt); 2) size detection limit, because in most dimensions of ENMs are between 1-100 nm (often smaller than $20 \mathrm{~nm}$ ); 3) aggregation state, because some NMs are not expected to preserve monodisperse state in the environment, the degree of their dispersion/aggregation is not static and will likely vary in time and is need ability to discern aggregated form single particle material; 4) naturally occurring nanomaterials, because their concentration in the environment are several orders of magnitude above that of engineered nanomaterials (ppm vs. ppt), and some natural nanoparticles have similar elemental composition and moreover morphologies to ENMs and natural nanoparticles tend to be very polydisperse and can interact with ENMs in the environment [20]. 
Table 1. Parameters for characterization of nanomaterials in the environment and proposal of possible analytical techniques, [11, 20, 22, 29, 32-35].

\begin{tabular}{|c|c|}
\hline Physiochemical properties & Analytical techniques \\
\hline Size (distribution) & $\begin{array}{l}\text { AFM, CE, DLS, EM, FI-FFF, FS, HDC, MALS, NTA, } \\
\text { SAXS, SEC, SEM, SP-ICP-MS, TEM, UV-vis, XRD }\end{array}$ \\
\hline \multicolumn{2}{|c|}{$\begin{array}{l}\text { Technical and analytical limitations: introduction of artifacts from sample drying (TEM/SEM); no } \\
\text { elemental specificity (DLS); inability to differentiate between ENMs and NNPs of similar } \\
\text { elemental composition (SP-ICP-MS, TEM, SEM); obstructed by high background of natural } \\
\text { particles (SP-ICP-MS, TEM, SEM, DLS, FFF) } \\
\text { Necessity: analysis of samples in situ with minimal sample preparation; elemental specificity to } \\
\text { differentiate between dissimilar nanomaterials; requires another measured property to differentiate } \\
\text { between particles of similar elemental composition }\end{array}$} \\
\hline $\begin{array}{c}\text { Surface } \\
\text { chemistry/charge/area/speciation }\end{array}$ & $\begin{array}{c}\text { AES, AFM, BET, EELS, FTIR, NMR, SEM, STM TEM, } \\
\text { XPS, Solid-state, Zeta potential by DLS, Fluorescence } \\
\text { labelling }\end{array}$ \\
\hline \multicolumn{2}{|c|}{$\begin{array}{l}\text { Technical and analytical limitations: original coating may have been replaced or overcoated in the } \\
\text { environment (NMR, FTIR, Zeta potential); ensemble techniques unable to characterize individual } \\
\text { particle populations without prior fractionation steps (FTIR, NMR, Zeta potential } \\
\text { Necessity: ability to differentiate between different particle populations in situ; knowledge of how } \\
\text { surface groups are attached may help determine if original coating persists }\end{array}$} \\
\hline $\begin{array}{l}\text { Concentration related to particle } \\
\text { number or mass }\end{array}$ & FS, GC-MS, MALS, NTA, ICP-MS, SP-ICP-MS, UV-vis \\
\hline \multicolumn{2}{|c|}{$\begin{array}{c}\text { Technical and analytical limitations: unable to determine aggregates form single particle without } \\
\text { parallel imaging/sizing technique; NTA is nonspecific for particle type } \\
\text { Necessity: require knowledge pertaining to aggregation state of ENMs }\end{array}$} \\
\hline Elemental composition & GC-MS, ICP-MS, ICP-OES, SP-ICP-MS, SEM/EDX, XPS \\
\hline \multicolumn{2}{|c|}{$\begin{array}{l}\text { Obstacles to accurate detection/characterization: unable to discern particles of natural or } \\
\text { engineered origin; may require acidification, eliminating particle integrity (ICP-MS, ICP-OES); } \\
\text { sample preparation may alter sample representativeness } \\
\text { Potential need: determination of elemental composition in situ with additional sample preparation }\end{array}$} \\
\hline Agglomeration/aggregation state & $\begin{array}{l}\text { AFM, CLSM, DLS, EM, FFF, FS, NTA, SEM, SP-ISP- } \\
\text { MS, TEM, UV-vis (for plasmonic nanoparticles) }\end{array}$ \\
\hline Shape & $\begin{array}{l}\text { AFM, CLSM, EM, FFF, SEM, TEM, UV-vis (for } \\
\text { plasmonic nanoparticles) }\end{array}$ \\
\hline Structure/crystallinity & ED, HR-TEM, SAED, SAXS, XRD \\
\hline Stability over time/dissolution & DLS, UV-vis, ICP-AES, ICP-MS, Colorimetric assays \\
\hline Dosing metric & Variable \\
\hline Uptake & $\begin{array}{l}\text { ICP-AES, ICP-MS, TEM, Fluorescence labelling, Flow } \\
\text { cytometry, NAA }\end{array}$ \\
\hline
\end{tabular}

Abbreviations:

AES - Auger electron Spectroscopy; AFM - Atomic Force Microscopy; BET - Brunauer, Emmett, Teller Method; CE - Capillary Electrophoresis; CLSM - Confocal Laser Scaning Microscopy; DLS - Dynamic Light Scattering; ED - Electron Diffraction; EDX - Energy Dispersive X-ray; EELS - Electron Energy Loss Spectrometry; EM - Electron Microscopy; FFF - Field Flow Fractionation; FI-FFF - Flow FFF; FS -Fluorescence Spectroscopy; FTIR - Fourier-TransformInfrared 
Spetroscopy; GC-MS - Gas Chromatography Mass Spectrometry; HDC - Hydrodynamic Chromatography; HR-TEM - High-resolution TEM; ICP-AES - Inductively Coupled Plasma Atomic Emission Spetrocsopy; ICP-MS - Inductively Coupled Plasma Mass Spectrometry; ICP-OES Inductively Coupled Plasma Optical Emission Spectrocsopy; MALS - Multi-AngleLightScattering; NAA - Neutron Activation Spectroscopy; NMR - Nuclear magneticresonanse Spectroscopy; NTA - Nanoparticle-Tracking Analysis; SAXS - Small Angle X-ray Scattering; SEC - Size Exclusion Chromatography; SAED - Selected Aera Electron Diffraction; SEM - Scanning Electron Microscopy; SP-ICP-MS - Single Particle ICP-MS; STM -Scanning Tunnelling Microscopy; TEM - Transmission Electron Microscopy; UV-vis - Ultraviolet-Visible Spectroscopy; XPS - X-ray Photoelectron Spectroscopy; XRD - X-ry Diffraction.

\section{Summary}

Nanotechnology is a multi-disciplinary field requiring the involvement and collaboration of scientists in many kind of disciplines such as material science, physics, chemistry, engineering, and social science. For this reason, the problem of nanosafety studies also depends on close cooperation between researchers from area of material science, chemistry, biology, toxicology and epidemiology, and risk assessment as well as representatives of industry, and policy makers. Also in this respect, education and upbringing of new generation of specialists in the field of nanosafety in the environment are needed. Additionally, activities to ensure the nanosafety must be integrated with nanotechnology progress. The most significant limitations are difficulties of ENMs separation from their natural counterparts. Solving of these technical problems for the proper risk assessment of nanomaterial and them characterization and monitoring in the environment are required. At the moment practical abilities of analysis and reliable quantification of nanomaterials in environmental samples are far away from robust, applicable and reproducible methods allowing their reliable monitoring.

\section{References}

1. A. Maynard, Nanotoday 1, 2 (2006)

2. G.E. Batley, J.K. Kirby, M.J. Mclaughlin, Accounts Chem. Res. 46, 3 (2013)

3. S. Singh, H. Singh Nalwa, J. Nanosci. Nanotechnol. 7, 9 (2007)

4. C. Remedios, F. Rosario, V. Bastos, Journal of Botany (2012)

5. F. Part, G. Zecha, T. Causon, E.K. Sinner, M.Huber-Humer, Waste Manage. 43 (2015)

6. Y. Kim, Environ. Health Toxicol. 29 (2014)

7. A.L. Holder, E.P. Vejerano, X. Zhoub, L.C. Marr, Environ. Sci. Processes Impacts, 15 (2013)

8. S.J. Klaine, P.J. Alvarez, G.E. Batley, T.F. Fernandes, R.D. Handy, D.Y. Lyon, S. Mahendra, M.J. McLaaughlin, J.R. Lead, Environ. Toxicol. Chem. 27, 9 (2008)

9. S. Smita, S.K. Gupta, A. Bartonova, M. Dusinska, A.C. Gutleb, Q. Rahman, Environ. Health 11, 1 (2012)

10. A. Keller, W. Vosti, H. Wang, A. Lazareva, J. Nanopart. Res. 16 (2014)

11. K. Savolainen, U. Backman, D. Brouwer, B. Fadeel, T. Fernandes, T. Kuhlbusch, R. Landsiedel, I. Lynch, L. Pylkkanen, Nanosafety in Europe 2015-2025: (Finnish Institute of Occupational Health, Helsinki 2013) (www.ttl.fi/en/publications/electronic_publications/pages/default.aspx)

12. C. Buzea, I.I. Pacheco Blandino, K. Robbie, Biointerphases 2, 4 (2007) 
13. Nanotechnology Risk Governance (International Risk Governance Council, Geneva 2007)

14. S.K. Brar, M. Verma, R.D. Tyagi, R.Y. Surampalli, Waste Manage. 30 (2010)

15. S. Singh, H. Singh Nalwa, J. Nanosci. Nanotechno. 7 (2007)

16. B. Kolodziejczyk, Brief for GSDR 2016 https://sustainabledevelopment.un.org/content/documents/9539GSDR_Nano brief\%20 $\underline{4 . p d f}$

17. G. Bystrzejewska-Piotrowska, J. Golimowski, P.L. Urban, Waste Manage. 29 (2009)

18. M. Crane, R.D. Handy, J. Garrod, R. Owen, Ecotoxicology, 17 (2008)

19. D. Ramakrishna, R. Pragna, The Journal Of The International Federation Of Clinical Chemistry And Laboratory Medicine 22, 4 (2011)

20. U.S. Environmental Protection Agency, Detection and Characterization of Engineered Nanomaterials in the Environment: Current State-of-the-Art and Future Directions (Washington, 2014)

21. G.V. Lowry, E.M. Hotze, E.S. Bernhardt, D.D. Dionysiou, J.A. Pedersen, M.R. Wiesner, B. Xing, J. Environ. Qual. 39 (2010)

22. European Commission Health and Consumer Protection Directorate-General. Directorate C - Public Health and Risk Assessment C7 - Risk assessment (2006)

23. A. Elsaesser, C.H. Howard, Adv. Drug Deliver. Rev. 64 (2012)

24. G.V. Lowry, K.B. Gregory, S.C. Apte, J.E. Lead, Environ. Sci. Technol. 46 (2012)

25. J. Swiatek-Prokop, Prace naukowe Akademii im. Jana Dlugosza w Czestochowie, Seria: Edukacja Techniczna i Informatyczna, VII (2012)

26. N. Musee, Hum. Exp. Toxicol. 30, 8 (2010)

27. N. Musee, Environmental International, 37 (2011)

28. G. Bystrzejewska-Piotrowska, J. Golimowski, P.L. Urban, Waste Manage. 29 (2009)

29. F. Part, G. Zecha, T. Causon, E.K. Sinner, M. Huber-Humer, Waste Manage. 43 (2015)

30. M. Maliszewska-Mazur, Ochr. Środ. i Zasob. Natur. 45 (2010)

31. P. Szewczyk, K. Midor, Zeszyty Naukowe Politechniki Slaskiej, Seria: Organizacja i Zarzadzanie 71, 1917 (2014)

32. S. Bandyopadhyay, J.R. Peralta-Videa, J. L. Gardea-Torresdey, Environ. Eng. Sci. 30, 3 (2013)

33. O. Posth, M.F. Hansen, U. Steinhoff, L. Bogart, P. Southern, P. Svedlindh, C. Gruttner, L. Fernandez Barquin, W. Szczerba, F. Ludwig, N. Gehrke, O. Kazakova, C. Johansson, In proceedings of IMEKO XXI World Congress (Czech Technical University, Prague, 2015)

34. P.C. Lina, S. Lina, P.C. Wanga, R. Sridharb, Biotechnol. Adv. 32. 4 (2014)

35. M. Hassello, J.W. Readman, J.F. Ranville, K. Tiede, Ecotoxicology, 17 (2008)

36. J.K. Patra, K.H. Baek, J. Nanomater. 2014 (2014) 